\section{A NEW SOCIAL CAPITAL SCALE: GEOGRAPHIC STABILITY COMPARED TO MOTHERS' PERSONAL SUPPORT AND DEPRESSIVE SYMPTOMS}

\author{
J. Pascoe ${ }^{1}$, C. McNicholas ${ }^{1}$, S. Specht ${ }^{1}$, \\ W. Spears ${ }^{1}$, W. Looman ${ }^{2}$
}

${ }^{1}$ Pediatrics, Wright State University, Dayton, $\mathrm{OH}$, ${ }^{2}$ Nursing, University of Minnesota, Minneapolis, MN, USA

Objective: To examine the geographic distribution of mothers' self-reported personal social support and depressive symptoms as well as their perception of their communities' social capital.

Design/methods: Birth mothers whose children were patients at practices within the Southwestern Ohio Ambulatory Research Network (SOAR-Net) and a developmental clinic completed a survey that included the Maternal Social Support Index (MSSI), the Center for Epidemiologic Studies Depression Scale (CES-D) and the Social Capital Scale (SCS). Data were collected between 2006 and 2009. English-speaking mothers who lived in one of the seven study zipcodes (ZC) with at least 22 mothers were included in this analysis (included zipcodes $\{\mid Z\}$, $\mathrm{N}=195$, excluded zipcodes $\{E Z\}, N=415)$. Inferential statistics included chi square, t-test and one-way anova.

Results: Mothers from IZ were more likely to be from SOAR-Net practices $(94.4 \%$ vs $80.7 \%$, $p=0.001)$, single $(42.7 \%$ vs $29.4 \%, p=0.001)$ and have a child with public health insurance $(69.5 \%$ vs $51.0 \%, p=0.001$ ) compared to mothers from $E Z$. Children's mean age (MA)was identical for both subgroups $(M A=6.3)$. None of the study variables (e.g., SCS, MSSI, CES-D) means were significantly different between the two subgroups (IZ and EZ). Though mean CES-D scores ranged from 9.4+/6.4 to $15.0+/-12.1$ across the seven IZ, they did not reach statistical significance $(p=0.148)$. Mean MSSI scores ranged from $27.5+/-4.9$ to $21.5+/-6.7$, $p=0.025$. Mean SCS scores had a notably narrow range $73.7+/-9.7$ to $70.7+/-9.7, p=0.950$ ).

Conclusions: Mothers' personal social support and depressive symptoms varied geographically across seven ZC more than a new measure of social capital developed for families raising disabled children.

\section{AUDIT OF CHILD PROTECTION REFERRALS IN A TERTIARY CENTRE IN THE UNITED KINGDOM}

\section{Palanivel ${ }^{1}$, M.A. Anjay², L. Preston ${ }^{3}$, E. Lewis ${ }^{4}$ \\ ${ }^{1}$ Department of Neurosciences, Great Ormond Street Hospital for Children, London, ${ }^{2}$ Department of Paediatrics, Addenbrookes Hospital, ${ }^{3}$ Department of Community Paediatrics, Addenbrooke's Hospital, ${ }^{4}$ Department of Community Paediatrics, Addenbrookes Hospital, Cambridge, UK}

Background and aims: Following the tragic death of an 8 year old girl called Victoria Climbie in 2000 due to child abuse, the British Government ordered a public inquiry to be chaired by Lord Laming into the circumstances surrounding her contact with each of the agencies and "the gross failure of the system to protect her". The report was published in January 2003. This report had 108 recommendations. Recommendations 64-90 were healthcare related. We aimed to measure compliance with the Laming recommendations in a tertiary hospital in the United Kingdom (UK) and to compare the results with a previous similar audit.

Methods: Retrospective study of case notes.All child protection referrals to social services over a period of 4 months were reviewed and 17 relevant case notes were selected for final analysis. Out of the 27 health care related recommendations, 81-90 were not within our clinical remit. 79 and 80 were considered not auditable from the case notes. The remaining 15 recommendations were audited.

Results: See Image 1

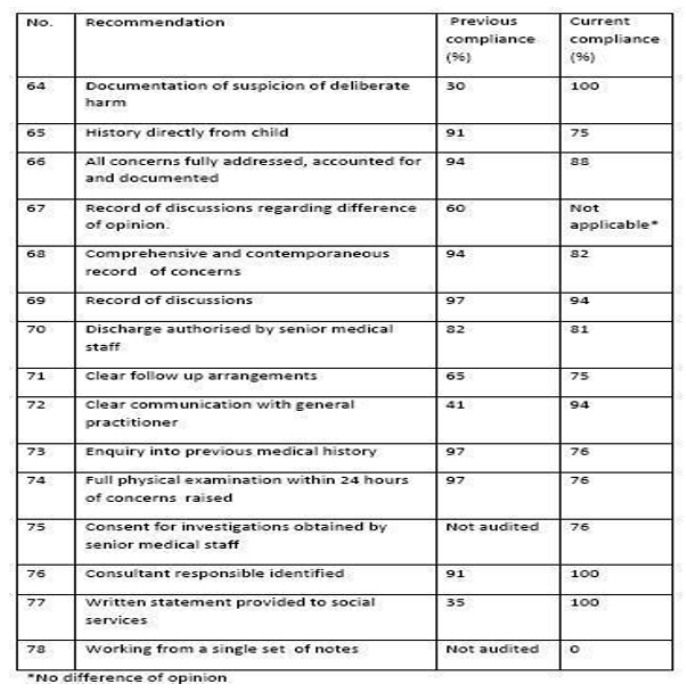

